\title{
Düşük risk prostat kanserinde nötrofil lenfosit oranı veya platelet lenfosit oranı tümörde evre yükselmesini öngörebilir mi?
}

\author{
Does neutrophil and platelets to lymphocyte ratios predict gleason score upgrading in \\ low-risk prostate cancer patients? \\ Yusuf Özlülerden, Sinan Çelen
}

Gönderilme tarihi:24.07.2020

Kabul tarihi:30.09.2020

\section{Özet}

Amaç: Düşük riskli prostat kanseri (PK) olan hastaların tedavi seçiminde, aktif izlem (Ai) ve aktif tedaviyi (AT) öngören bazı karar verme araçları pahalı olması nedeni ile kolayca erişilebilir değildir. Bu nedenle, biz bu çalışmamızda PK'lı hastaların preoperatif olarak doğru evrelendirilmesi için farklı, kolay, ulaşılabilir bir parametre belirlemeyi amaçladık.

Gereç ve yöntem: Radikal prostatektomi uygulanan ve klinik evre T2a, Gleason skor (GS) $\leq 6$, prostat spesifik antijen seviyesi $<10 \mathrm{ng} / \mathrm{mL}$ parametrelerini karşılayan 59 hastanın kayıtları retrospektif olarak incelendi. Hastaların yaşları, preoperatif prostat spesifik antijen değerleri (PSA), nötrofil lenfosit oranı (NLO), trombosit lenfosit oranı (PLO), patolojik evresi, patolojik gleason skoru belirlenerek, gruplar arası karşılaştırmalı analizi yapıldı (Klinik evre veya gleason skorunda artış gibi).

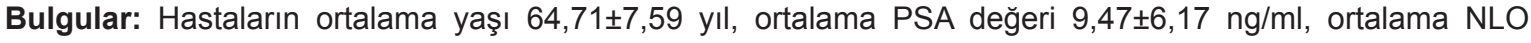
$1,86 \pm 0,76$ ve ortalama PLO 103,13 $\pm 32,8$ 'dir.

Sonuç: Sonuçlarımız NLO, PLO değerlerinde artışın gleason skoru ve evre artışı ile ilişkili olmadığını göstermiştir. Bu nedenle, bu parametreler Al için hasta belirlenmesinde yararlı olmayabilir.

Anahtar kelimeler: Prostat kanseri, nötrofil lenfosit oranı, trombosit lenfosit oranı.

Çelen S, Özlülerden Y. Düşük risk prostat kanserinde nötrofil lenfosit oranı veya platelet lenfosit oranı tümörde evre yükselmesini öngörebilir mi? Pam Tıp Derg 2021;14:119-124.

\begin{abstract}
Purpose: Some of decision-making factors predicting treatment selection, active surveillance (AS) and active treatment (AT), are expensive and not easily accessible in patients with a low-risk prostate cancer (PCa). Therefore, in this study, we aimed to determine a different, easy, achievable parameter for preoperatively correct staging of patients with PCa.

Materials and methods: We retrospectively reviewed the records of 59 men undergoing radical prostatectomy with clinical stage T2a PCa, Gleason score (GS) $\leq 6$ grade, prostate-specific antigen level $<10 \mathrm{ng} / \mathrm{mL}$. The patients' ages, preoperative prostate specific antigen (PSA) lymphocyte ratio (NLR) or platelets to lymphocyte ratio (PLR), pathologic stage, pathologic Gleason score, tumor volume, were noted and compared between groups (upgrade or not upgrade, upstage or not upstage)

Results: The mean age of patients was $64.71 \pm 7.59$ years, mean PSA value was $9.47 \pm 6.17 \mathrm{ng} / \mathrm{Ml}$, mean NLR was $1.86 \pm 0.76$ and mean PLR ratio was $103.13 \pm 32.8$. We found that NLR and PLR upgrading were not significantly associated with upgrading or upstaging.

Conclusion: Our results showed that NLR, PLR, are not predictors of Gleason and stage upgrading. Therefore, these tests might not be useful in the assessment of low-risk PCa, when considering patients for AS.
\end{abstract}

Key words: Prostate cancer, platelets to lymphocyte ratio, neutrophil to lymphocyte ratio.

Celen S, Ozlulerden Y. Does neutrophil and platelets to lymphocyte ratios predict gleason score upgrading in low-risk prostate cancer patients? Pam Med J 2021;14:119-124.

Yusuf Özlülerden, Dr. Öğr. Üye. Pamukkale Üniversitesi Tıp Fakültesi Üroloji Anabilim Dalı, Denizli, Türkiye, e-posta: yusufozlu35@hotmail.com (orcid.org/0000-0002-6467-0930)

Sinan Çelen, Dr. Öğr. Üye. Pamukkale Üniversitesi Tıp Fakültesi Üroloji Anabilim Dalı, Denizli, Türkiye, e-posta: sinancelen@ hotmail.com (orcid.org/0000-0003-4309-2323) (Sorumlu Yazar) 


\section{Giriş}

Prostat spesifik antijenin (PSA) yaygın kullanımı erken evrelerde teşhis edilen prostat kanseri (PK) sayısında artış görülmesini neden oldu ancak buna paralel olarak klinik önemsiz PK sayısında da önemli oranda artışa neden oldu [1, 2]. Düşük riskli prostat kanserinde bir tedavi şekli olarak bekle-gör seçeneği tercihinde \%0'dan \%39'a varan bir artı̧̧ görülmüştür [3].

PIVOT çalışması aktif izlemin (Ai) önemini gösteren bir çalışma olup, $A \dot{I}$ tercihinde klinik T evresi, PSA değeri, PSA yoğunluğu, Gleason skoru (GS) ve pozitif kor sayısı gibi parametrelerin seçim ve takip için belirleyici olduğu gösterilmiştir [4].

Bununla birlikte pozitif prostat biyopsi kor sayısı Al için uygun olan bazı hastaları yanlış bir şekilde dışlamakta ve önemli hastalığı olan bazılarını yanlış sınıflandırmaktadır [5]. $\mathrm{Bu}$ duruma ek olarak, Al belirlenmesinde kullanılan PSA, dijital rektal muayene ve biyopsi sonuçları gibi mevcut diğer preoperatif parametreler PK agresifliğini doğru bir şekilde tahmin edememekte ve önemsiz PK ile klinik olarak anlamlı PK'ni ayırt etmekte yetersiz olabilmektedir [6].

GS artışını tahmin etmek için valide edilmiş bir öngörücü modele dahil edilen bu değişkenlerin yanı sıra, bir dizi biyomoleküler belirteç GS yükselmesi ile ilişkilendirilmiştir. Yakın zamanda yayınlanan çalışmalarda, prostat kanseri antijeni 3 (PKA3), sarkosin, proPSA ve Prostat Sağlığı Indeksi gibi diğer birçok preoperatif prognostik parametrelerin radikal prostatektomide (RP) patolojik özellikleri tahmin etme yeteneği analiz edilmiştir [7, 8]. Artmış nötrofil-lenfosit oranı (NLO), farklı kanser türlerinde kansere bağlı inflamasyon ve olumsuz prognozun bir göstergesi olarak belirlenmiştir $[9,10]$. PK'da yüksek NLO, metastatik hastalarda kanserin agresifliği ile ilişkililendirilmiştir. Preoperatif NLO'nin RP sonrası genel ve kansere özgü sağkalım için bağımsız bir prognostik faktör olduğu gösterilmiştir [11]. Bir diğer çalışmada daha yüksek GS'nin yüksek NLO ile ilişkili olduğunu gösterilmiştir. Bu çalışmada, düşük riskli PK hastalarında NLO ve trombosit lenfosit oranının (TLO) prostat kanserinde evre artışını öngörmedeki rolü değerlendirilmiştir [12].

\section{Gereç ve yöntem}

Kasım 2017 ile Şubat 2020 tarihleri arasında arasında prostat kanseri nedeni ile RP uygulanan hastaların tıbbi kayıtları retrospektif olarak incelendi. Çalışma için, Pamukkale Üniversitesi Girişimsel Olmayan Klinik Araştırmalar Etik Kurulu'nun onayı alınmıştır. $\mathrm{Bu}$ çalışmaya dahil edilen hiçbir hastaya neoadjuvan androjen baskılama tedavisi veya PSA değerlerini değiştirebilecek medikal tedavi verilmemiştir. Hastaların hiçbirinde finasterid tedavisi öyküsü veya RP öncesine ait prostat cerrahisi öyküsü yoktu. Akut prostatit bulgusu olan veya eksik verisi olan hastalar çalışma dışı bırakıldı. Veri analizi sonucunda klinik evre T2a veya $T 1 \mathrm{c}, \mathrm{PSA}<10 \mathrm{ng} / \mathrm{mL}$ olan, kanserle ilişkili 2 veya daha az pozitif kor sayısı olan ve GS grade 6 olan hastalar çalışmaya dahil edildi. RP sonrasında prostatbiyopsileriile RP spesmeninin patolojik bulguları karşılaştıııldı. RP örnekleri, Uluslararası Ürolojik Patoloji Derneği'nin 2005 konsensüs konferansının tanımlarına göre değerlendirilmiş ve derecelendirilmiştir [13]. Patolojik inceleme sonrası evre veya gleason derecesinde artış olan veya olmayan hastalarda PLO ve NLO'lar karşılaştırıldı.

Sürekli değişkenlerin (yaş, PSA, prostat hacmi, NLO, PLO) dağılımları KolmogorovSmirnov testi ile normallik açısından değerlendirildi. Prostat kanserinde evre artışı ile NLO ve PLO arasındaki ilişkisini değerlendirmek için indepentent $\mathrm{t}$ test analizi veya parametrik olmayan 2 örnekli Wilcoxon testi uygulandı. İstatistiksel anlamlılık $p<0,05$ olarak tanımlandı. Verilerin değerlendirilmesinde SPSS 22 (SPSS Inc., Chicago IL, USA) istatistik programı kullanıldı.

\section{Bulgular}

Hastaların tamamında preoperatif klinik evre cT1c olarak belirlendi. Postoperatif dönemde hastaların \%66'inde patolojik evre pT2 ve \%44'ünde pT3 saptandı. Toplam 22 hastada GS=6, 37 hastada ise $G S=7$ ve üstü idi. Hastaların yaş ortalaması $64,71 \pm 7,59$ yıl, ortalama PSA değerleri $9,47 \pm 6,17$ idi (Tablo 1). Bağımsız $T$ testi analizi ile yapılan değerlendirmede evre veya gleason grade artışı olan ve olmayan hastalarda NLO ve PLO arasında fark yoktu (Tablo 2, 3). 
Tablo 1. Hasta özellikleri

\begin{tabular}{ll}
\hline & Mean \pm SD ve $n(\%)$ \\
\hline PSA (ng/mL) & $9,47 \pm 6,17$ \\
Yaş (yıl) & $64,71 \pm 7,59$ \\
Prostat hacmi & $45,27 \pm 27,26$ \\
Nötrofil/Lenfosit oranı & $1,86 \pm 0,76$ \\
Trombosit/Lenfosit oranı & $103,13 \pm 32,8$ \\
Klinik evre & \\
cT1c & $59(100)$ \\
Patolojik evre & \\
T2a & $13(22)$ \\
T2b & $1(1,7)$ \\
T2c & $25(42,4)$ \\
T3a & $25(25,4)$ \\
T3b & $5(8,5)$ \\
Gleason skoru & \\
6 & $22(37,3)$ \\
7 & $33(55,9)$ \\
8 & $2(3,4)$ \\
9 & $1(1,7)$ \\
10 & $1(1,7)$ \\
Gleason skroru yükselmesi (GS $>7)$ & \\
Evet & $37(62,7)$ \\
Hayır & $22(37,3)$ \\
Evre yükselmesi (pT >3a) & \\
Evet & $20(33,9)$ \\
Hayır & \\
\hline & \\
\hline & \\
\hline
\end{tabular}

Saphiro-wilk

Tablo 2. Gleason skoru yükselmesine göre değişkenler arası farklılık

\begin{tabular}{|c|c|c|c|}
\hline & \multicolumn{3}{|c|}{ Gleason skrounda artış } \\
\hline & Evet & Hayır & $p$ değeri \\
\hline PSA (ng/dl) & $10,4 \pm 6,95$ & $7,91 \pm 4,27$ & 0,134 \\
\hline Yaş (yıl) & $60,22 \pm 8$ & $63,86 \pm 6,93$ & 0,513 \\
\hline Prostat hacmi & $42,7 \pm 31,1$ & $49,5 \pm 19$ & 0,352 \\
\hline Nötrofil/Lenfosit oranı & $1,99 \pm 0,81$ & $1,64 \pm 0,63$ & 0,086 \\
\hline Trombosit/Lenfosit oranı & $101,92 \pm 33,51$ & $105,17 \pm 32,2$ & 0,716 \\
\hline
\end{tabular}


Tablo 3. Evre artışına göre değişkenler arası farklılık

\begin{tabular}{llll}
\hline & Evre artışı & & \\
\hline & Evet & Hayır & $p$ değeri \\
PSA (ng/dl) & $10,48 \pm 6,51$ & $8,96 \pm 6$ & 0,375 \\
Yaş (yıl) & $66,05 \pm 8,53$ & $64,03 \pm 7,08$ & 0,337 \\
Prostat hacmi & $44,75 \pm 38,55$ & $45,53 \pm 19,77$ & 0,917 \\
Nötrofil/Lenfosit oranı & $1,93 \pm 0,882$ & $1,82 \pm 0,708$ & 0,597 \\
Trombosit/Lenfosit oranı & $103,27 \pm 39,99$ & $103,06 \pm 29,6$ & 0,981 \\
\hline
\end{tabular}

\section{Tartışma}

Aİ, RP ile ilişkili komplikasyonları önleyebilen bir seçenek olmaya devam etmektedir. Özellikle düşük riskli $\mathrm{PK}$ olan hastalar için bu komplikasyonların önüne geçebilmek hayat kalitesini daha iyi olabilmesi açısından önemlidir. Şu anda, risk sınıflamasını belirlemek için D'Amico sınıflaması (klinik aşama, GS ve PSA) uygulanmakta ve buna göre tedavi şeması seçilmektedir. Bununla birlikte GS artışı halen büyük bir endişe kaynağıdır. Literatür verileri RP sonrası yaklaşık \%30 oranında GS artışı olduğunu göstermektedir. Son zamanlarda Al için en uygun hastaları seçmenin bir yolu olarak önerilen çeşitli klinik ve biyokimyasal parametreler olmasına rağmen, kanser risk sınıfının yanlış değerlendirilmesi veya yüksek riskli bir kanseri yanlış tanımlamak hala sorun olmaya devam etmektedir [14-16]. Bazı yazarlar tümör mikroçevresindeki inflamatuar yanıtın kanser malign fenotipinde anahtar rol oynadığını bildirmiştir [17, 18]. Bu temelde, kan örneklerinden elde edilen bağışıklık hücreleri ile ilgili veriler bunların potansiyel olarak kanser hastalarında prognostik prediktör olarak değerlendirilebilinmektedir [19]. Birçok çalışmada NLO ve PLO'nun tümör evre artışı ile ilişkili olabileceği gösterilmiştir [20, 21]. Bu çalışmada, yüksek NLO ve PLO'nun evre veya GS ile ile ilişkili olmadığı sonucuna ulaştık.

Yüksek NLO'nun hormon dirençli prostat kanseri hastalarında agresif hastalık ile ilişkili olduğu ve ilaç direncinin bir göstergesi olduğu gösterilmiş olup, daha yakın zamanlarda, düşük NLO'nun düşük riskli PK'li hastalarda GS iyileşmesi ve biyokimyasal nüksün bir göstergesi olduğu bildirilmiştir [22]. Yapılan diğer çalışmalarda, yüksek PLO'nun radyoterapi ile tedavi edilen PK hastalarında kötü prognozun bir göstergesi olduğu gösterilmiştir [23]. Ayrıca, bazı çalışmalarda trombositlerin metastaz, anjiyogenez ve invazivlik gibi kanserin agresif yönde ilerlemesine katkı sağladığı gösterilmiştir $[24,25]$. Son zamanlarda yapılan bir çalışmada, beyaz küre hücrelerinin $(\mathrm{BKH})$ alt grupları ile yüksek GS arasındaki ilişki araştırıımış ve BKH'lerin serum monosit alt grubunun yüksek GS ile ilişkili olduğu bildirilmiştir [26].

İnterlökin-6 ve tümör nekroz faktörü- $\alpha$ serum düzeylerinin, prostat kanseri hastalarının klinik sonuçları ile ilişkili olduğu bildirilmiştir [27]. NLO ve PLO'nun tümör gelişimi ve metastazı sürecinde süregelen mikro ortamı yansıttığı düşünülmektedir [28]. Düşük riskli PK hastalarında, bu hematolojik belirteçlerin kullanımı agresif tümörlere sahip hastaları tanımlamak için yararlı olabilir. Bu nedenle, bu testler cerrahi tedaviden kimin faydalanabileceğini belirlemek amacı ile düşük riskli PK hastalarının klinik yönetiminde uygulanabilir. Daha büyük popülasyonla ilgili daha fazla çalışma, dolaşımdaki her spesifik immün hücre indeksinin klinik karar seçimi üzerindeki etkisi araştırmalıdır. Çalışmamızın retrospektif olması, C-reaktif protein gibi diğer sistemik enflamatuar parametrelerin değerlendirilmeye dahil edilmemiş olması, çalışmamızdaki hasta sayısının sınırlı olması bu çalışmanın sınırlılıklarıdır. Sonuç olarak, artmış NLO ve PLO'nun RP uygulanan PK hastalarında GS artışı ile ilişkili olmayabileceği sonucuna ulaşılmıştır. $\mathrm{Bu}$ nedenle, uygun maliyetli ve kolayca ölçülebilen bu hematolojik testler, daha büyük çalışma popülasyonunda valide edilmelidir.

Çıkar ilişkisi: Yazarlar çıkar ilişkisi olmadığını beyan eder. 


\section{Kaynaklar}

1. Moyer VA. U.S. Preventive Services Task Force. Screening for prostate cancer: U.S. preventive services task force recommendation statement. Ann Intern Med 2012;157:120-134. https://doi.org/10.7326/0003-4819157-2-201207170-00459

2. Bastian $\mathrm{PJ}$, Carter $\mathrm{BH}$, Bjartell $\mathrm{A}$, et al. Insignificant prostate cancer and active surveillance: from definition to clinical implications. Eur Urol 2009;55:1321-1332. https://doi.org/10.1016/j.eururo.2009.02.028

3. McVey GP, McPhail S, Fowler S, McIntosh G, Gillatt D, Parker CC. Initial management of low-risk localized prostate cancer in the UK: analysis of the British association of urological surgeons cancer registry. BJU Int 2010;106:1161-1164. https://doi.org/10.1111/j.1464410X.2010.09288.x

4. Wilt TJ, Brawer MK, Jones KM, et al. Radical prostatectomy versus observation for localized prostate cancer. N Engl J Med 2012;367:203-213. https://doi. org/10.1056/NEJMoa1113162

5. Faria EF, Chapin BF, Muller RL, Machado RD, Reis RB, Matin SF. Radical prostatectomy for locally advanced prostate cancer: current status. Urology 2015;86:1015. https://doi.org/10.1016/j.urology.2015.03.012

6. Tran E, Paquette M, Pickles T, et al. Population-based validation of a policy change to use long-term androgen deprivation therapy for cT3-4 prostate cancer: impact of the EORTC22863 and RTOG 85-31 and 92-02 trials. Radiother Oncol 2013;107:366-371. https://doi. org/10.1016/j.radonc.2013.05.003

7. D'Amico AV, Whittington $\mathrm{R}$, Malkowicz SB, et al. Biochemical outcome after radical prostatectomy, external beam radiation therapy, or interstitial radiation therapy for clinically localized prostate cancer. JAMA 1998;280:969-974. https://doi.org/10.1001/ jama.280.11.969

8. Cantiello F, Russo GI, Ferro M, et al. Prognostic accuracy of Prostate Health Index and urinary Prostate Cancer Antigen 3 in predicting pathologic features after radical prostatectomy. Urol Oncol 2015;33:163.15-23. https://doi.org/10.1016/j.urolonc.2014.12.002

9. Ozmen S, Timur O, Calik I, et al. Neutrophillymphocyte ratio (NLR) and platelet-lymphocyte ratio (PLR) may be superior to C-reactive protein (CRP) for predicting the occurrence of differentiated thyroid cancer. Endocr Regul 2017;51:131-136. https://doi.org/10.1515/enr2017-0013

10. Lee YS, Nam HS, Lim JH, et al. Prognostic impact of a new score using neutrophil-to-lymphocyte ratios in the serum and malignant pleural effusion in lung cancer patients. BMC Cancer 2017;17:557. https://doi. org/10.1186/s12885-017-3550-8
11. Jang WS, Cho KS, Kim MS, et al. The prognostic significance of postoperative neutrophil-to-lymphocyte ratio after radical prostatectomy for localized prostate cancer. Oncotarget 2017;8:11778-11787. https://doi. org/10.18632/oncotarget.14349

12. Gokce MI, Hamidi N, Suer E, Tangal S, Huseynov A, Ibis A. Evaluation of neutrophilto-lymphocyte ratio prior to prostate biopsy to predict biopsy histology: results of 1836 patients. Can Urol Assoc J 2015;9:761-765. https://doi.org/10.5489/cuaj.3091

13. Roobol MJ, Verbeek JF, van der Kwast T, Kummerlin IP, Kweldam CF, van Leenders GJ. Improving the rotterdam European randomized study of screening for prostate cancer risk calculator for initial prostate biopsy by incorporating the 2014 international society of urological pathology gleason grading and cribriform growth. Eur Urol 2017;72:45-51. https://doi. org/10.1016/j.eururo.2017.01.033

14. Cary KC, Cooperberg MR. Biomarkers in prostate cancer surveillance and screening: past, present, and future. Ther Adv Urol 2013;5:318-329. https://doi. org/10.1177/1756287213495915

15. de Cobelli O, Terracciano D, Tagliabue E, et al. Body mass index was associated with upstaging and upgrading in patients with lowrisk prostate cancer who met the inclusion criteria for active surveillance. Urol Oncol 2015;33:201-208. https://doi.org/10.1016/j. urolonc.2015.02.004

16. Ferro M, Lucarelli G, Bruzzese D, et al. Low serum total testosterone level as a predictor of upstaging and upgrading in low-risk prostate cancer patients meeting the inclusion criteria for active surveillance. Oncotarget 2017;8:18424-18434. https://doi.org/10.18632/ oncotarget. 12906

17. Grivennikov SI, Greten FR, Karin M. Immunity, inflammation, and cancer. Cell 2010;140:883-899. https://doi.org/10.1016/j.cell.2010.01.025

18. Hanahan D, Weinberg RA. Hallmarks of cancer: the next generation. Cell 2011;144:646-674. https://doi. org/10.1016/j.cell.2011.02.013

19. Wei $Y$, Jiang $Y Z$, Qian $W H$. Prognostic role of NLR in urinary cancers: a meta-analysis. PLoS One 2014;9:92079. https://doi.org/10.1371/journal. pone.0092079

20. Wu Y, Li C, Zhao J, et al. Neutrophil-to-lymphocyte and platelet-to-lymphocyte ratios predict chemotherapy outcomes and prognosis in patients with colorectal cancer and synchronous liver metastasis. World J Surg Oncol 2016;14:289. https://doi.org/10.1186/s12957016-1044-9

21. Bagante F, Tran TB, Postlewait LM, et al. Neutrophillymphocyte and platelet-lymphocyte ratio as predictors of disease specific survival after resection of adrenocortical carcinoma. J Surg Oncol 2015;112:164172. https://doi.org/10.1002/jso.23982 
22. van Soest RJ, Templeton AJ, Vera Badillo FE, et al. Neutrophil-to-lymphocyte ratio as a prognostic biomarker for men with metastatic castration-resistant prostate cancer receiving first-line chemotherapy: data from two randomized phase III trials. Ann Oncol 2015;26:743-749. https://doi.org/10.1093/annonc/ mdu569

23. Langsenlehner $\mathrm{T}$, Pichler $\mathrm{M}$, Thurner $\mathrm{EM}$, et al. Evaluation of the platelet-to-lymphocyte ratio as a prognostic indicator in a European cohort of patients with prostate cancer treated with radiotherapy. Urol Oncol 2015;33:201.9-16. https://doi.org/10.1016/j. urolonc.2015.02.002

24. Bakewell SJ, Nestor P, Prasad S, et al. Platelet and osteoclast beta3 integrins are critical for bone metastasis. Proc Natl Acad Sci U S A 2003;100:1420514210. -https://doi.org/10.1073/pnas.2234372100

25. Smyth SS, McEver RP, Weyrich AS, et al. Platelet functions beyond hemostasis. J Thromb Haemost 2009;7:1759-1766. https://doi.org/10.1111/j.15387836.2009.03586.x

26. Hayashi T, Fujita K, Tanigawa G, et al. Serum monocyte fraction of white blood cells is increased in patients with high gleason score prostate cancer. Oncotarget 2017;8:35255-35261. https://doi.org/10.18632/ oncotarget. 13052

27. Michalaki V, Syrigos $K$, Charles $P$, Waxman J. Serum levels of IL-6 and TNF-alpha correlate with clinicopathological features and patient survival in patients with prostate cancer. Br J Cancer 2004;90:23122316. https://doi.org/10.1038/sj.bjc.6601814

28. Mantovani A, Allavena P, Sica A, Balkwill F. Cancerrelated inflammation. Nature 2008;454:436-444. https://doi.org/10.1038/nature07205

Etik kurul onayı: Çalışma, Pamukkale Üniversitesi Girişimsel Olmayan Klinik Araştırmalar Etik Kurulu'nun 22/05/2019 tarih ve $60116787-020 / 35540$ sayılı toplantı onay alınmıştır.

\section{Yazarların makaleye olan katkıları}

S.Ç. çalışmanın ana fikrini ve hipotezini kurgulamış/kurgulamışlardır. S.Ç., Y.Ö. teoriyi geliştirmiş ve materyel metod bölümünü düzenlemiş/düzenlemişlerdir. Sonuçlar kısmındaki verilerin değerlendirmesini yapmışlardır. Makalenin tartışma bölümü S.Ç., Y.Ö. tarafından yazılmış, S.Ç., Y.Ö. gözden geçirip gerekli düzeltmeleri yapmış ve onaylamıştır. Ayrıca tüm yazarlar çalışmanın tamamını tartışmış ve son halini onaylamıştır. 